\title{
Characterization of lacustrine iron sulfide particles with proton-induced X-ray emission
}

\begin{abstract}
Black particles, collected by filtration $(1.2-\mu \mathrm{m}$ pore size) from the anoxic waters of a soft-water lake, were examined by a scanning proton microprobe which permitted quantitative elemental analysis by proton-induced X-ray emission (PIXE) and Rutherford backscattering (RBS). There was a uniform distribution of sulfur across the filter, but $\mathrm{Fe}$, and to a lesser extent, $\mathrm{Mn}$, was localized in $\sim 5-\mu \mathrm{m}$-diameter clusters. Elemental analysis with $1-\mu \mathrm{m}$-diameter beams revealed that the $\mathrm{Fe}$ clusters were mainly comprised of iron oxides. Iron sulfide material not in the Fc clusters had stoichiometric proportions of $\mathrm{Fe}_{1.0} \mathrm{~S}_{0.60} \mathrm{P}_{0.60} \mathrm{Ca}_{0.24} \mathrm{~K}_{0.14}$. Although a purely biogenic origin for $\mathrm{P}, \mathrm{Ca}$, and $\mathrm{K}$ cannot be ruled out, the composition is consistent with the particles originating as authigenic iron oxides which react with sulfide as they sink through the water column. The iron sulfide particles are richer in $\mathrm{Cu}$ $(4,000 \mathrm{ppm})$ and $\mathrm{Zn}(6,000 \mathrm{ppm})$ than the iron oxides, suggesting that these elements are also concentrated as their insoluble sulfides. The coexistence of iron oxides and sulfides indicates that either the supply of sulfide is limiting or that some iron oxide particles are unreactive.
\end{abstract}

Black particles of iron sulfide have been clearly observed when the bottom waters of seasonally anoxic lakes are filtered (Davison and Heaney 1978; Cook 1984). Evidence for their iron sulfide composition has come from the ion activity product, IAP $=a \mathrm{Fe}^{2+}$ $\times a \mathrm{HS}^{-} /\left(\mathrm{H}^{+}\right)$, which in many lakes has been found to be constant with depth, indicating control of the concentration of solution species by the solid phase (Davison 1991). For a wide variety of waters the IAP falls in a narrow range (pIAP $=2.6-3.22$ ) which agrees with the measured solubility product for amorphous ferrous sulfide of $\mathrm{pK}_{\mathrm{sp}}=$ $2.95 \pm 0.1$.

These iron sulfide particles have been poorly characterized, partly because of the

\footnotetext{
Acknowledgments

We thank John Hamilton-Taylor for comments on an earlier draft and the Natural Environment Research Council for funding this work. The operation of the scanning proton microprobe facility is supported in part by the Wellcome Trust.
}

difficulties of performing measurements on samples that are very sensitive to oxygen. When the ratio of $\mathrm{Fe}(\mathrm{II})$ to $\mathrm{S}$ (-II) has been measured colorimetrically or polarographically, a stoichiometric excess of $\mathrm{Fe}(\mathrm{II})$ has been observed in both larger $(>0.8 \mu \mathrm{m})$ (Davison and Dickson 1984) and colloidalsized $(<0.45 \mu \mathrm{m})$ (Buffle et al. 1987) particles. Mossbauer spectroscopy has confirmed this imbalance and led to the suggestion that the particles may comprise iron oxyhydroxides with a surface coating of sulfide (Davison and Dickson 1984). For a hard-water lake it was hypothesized that the stoichiometric excess of $\mathrm{Fe}$ may be due to the presence of siderite (Buffle et al. 1987), but Davison and Heaney (1978) failed to find any carbonate in their similar samples from a soft-water lake.

Recent studies have shown a direct association between the geochemical cycling of selected trace metals in lakes and the active redox cycling of $\mathrm{Fe}$ and $\mathrm{Mn}$ (Morfett et al. 1988; Balistrieri et al. 1992). However, to our knowledge, there are no reports of the trace element composition of iron sulfide particles.

This note attempts to rectify some of the above deficiencies by examining iron sulfide particles with nuclear microscopy (Grime and Watt 1990) at the Oxford University scanning proton microprobe (SPM) facility (Grime et al. 1991). This technique uses a beam of high-energy ( $>2 \mathrm{MeV}$ ) protons focused to a diameter of $1 \mu \mathrm{m}$ and is capable of elemental mapping and quantitative microanalysis for elements throughout the periodic table by means of various ion-solid interactions. The analytical techniques used in this study are PIXE (proton-induced $\mathrm{X}$-ray emission) (Johansson and Campbell 1988) which gives ppm detection limits for all elements with $Z>12$, and RBS (Rutherford backscattering) (Chu et al. 1978) which uses the measured energy of recoiling protons to determine the concentrations and 

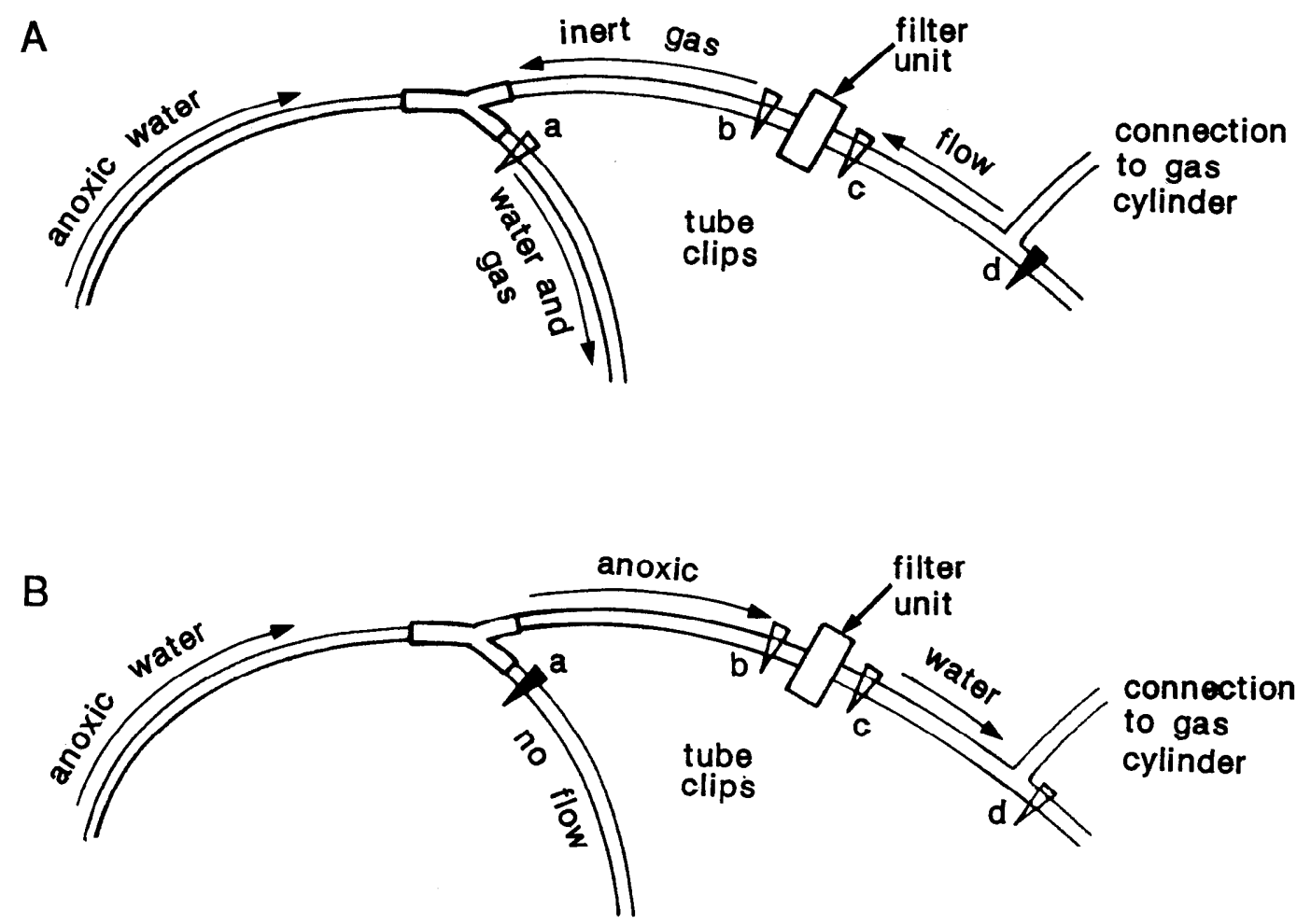

Fig. 1. Schematic diagram showing the arrangement of tubing regulating the supply of anoxic water and inert gas for the collection of particles under anoxic conditions. A. The initial flushing of gas through the filter. B. The collection of particles as anoxic water flows through the filter. Triangles indicate closed $(\nabla)$ and open $(\nabla)$ valves.

depth distribution of light major elements (including oxygen and nitrogen) in the sample. These techniques are used simultaneously, giving the possibility of total quantitative elemental analysis with micron spatial resolution. At the same time, secondary electrons are detected to give topographical images of the sample.

Iron sulfide particles were collected on 20 September 1989 from Esthwaite Water, a seasonally anoxic, soft-water, circumneutral lake whose redox chemistry and iron sulfide particles have been studied extensively (Davison and Heaney 1978; Davison and Dickson 1984; Davison 1991). The lake is $15 \mathrm{~m}$ deep and at this time of year it is typically anoxic at depths $>8 \mathrm{~m}$. Representative water composition for mid-September at $14 \mathrm{~m}$ deep is $\left(\mathrm{mmol}\right.$ liter $\left.{ }^{-1}\right): \mathrm{Ca}^{2+}$, $0.27 ; \mathrm{Mg}^{2+}, 0.06 ; \mathrm{Na}^{+}, 0.26 ; \mathrm{K}^{+}, 0.03$; $\mathrm{NH}_{4}^{+}, 0.08 ; \mathrm{Fe}^{2+}, 0.15 ; \mathrm{Mn}^{2+}, 0.06 ; \mathrm{Cl}^{-}$, $0.27 ; \mathrm{SO}_{4}^{2-}, 0.13 ; \mathrm{S}(-\mathrm{II}), 0.004$. Alkalinity,
$\mathrm{pH}$, and dissolved reactive $\mathrm{P}$ are typically 0.9 meq liter ${ }^{-1}, 6.9$, and $0.01 \mathrm{mmol} \mathrm{liter}^{-1}$. A battery-operated peristaltic pump was used to collect anoxic water from $14 \mathrm{~m}$ deep. It was fed directly to a tubing arrangement (Fig. 1) in which a 47-mm cellulose acetate filter $(1.2-\mu \mathrm{m}$ pore size) in a Swin-lok (Nuclepore) holder was continually backflushed with inert gas. By closing clip a and opening clip d, 100-200 ml of anoxic water was directed through the filter. After $\sim 1$ min clip a was opened and clip d closed, causing the filter to be flushed again with inert gas. Clips $\mathrm{b}$ and $\mathrm{c}$ were then closed to isolate the filter unit. The tubing was disconnected between clips $a$ and $b$ and clips $c$ and $d$, allowing the holder and clips $b$ and $c$ to be plunged immediately into a 2-liter anaerobic chamber containing nitrogen gas and a palladium catalyst. The transfer operation was conducted under a hood of inert gas. Within $1 \mathrm{~h}$, on returning to the laboratory, the anaerobic 
chamber was further flushed with a mixture of $\mathrm{N}_{2}-\mathrm{H}_{2}$.

Less than $24 \mathrm{~h}$ later the chamber was opened in a nitrogen-flushed cabinet and the filter mounted on a stub. This assembly was transferred in a sealed container to an anaerobic bag on the microprobe sample port that was flushed with nitrogen, facilitating anaerobic sample presentation before establishing a vacuum.

The material on the filter was analyzed with a beam of $2 \mathrm{MeV}$ protons focused to $1-\mu \mathrm{m}$ diameter. The SPM was used in scanning mode to indicate the distribution of each element and, in addition, the beam was positioned at selected points to provide analytical information for a $1-\mu \mathrm{m}$-diameter circle. The PIXE and RBS energy spectra from the point analyses were processed numerically (Jaksic et al. 1991) to give element concentrations. The PIXE results require correction for stopping of the proton passing through the sample and for absorption of the emitted X-rays. The correction is calculated with the sample thickness and stoichiometry determined from RBS data. (For the results presented here, the samples are thin, and the corrections are in general small.) Because the thin layer of sediment on the filter is of nonuniform thickness, the concentrations derived from the PIXE data were calculated as areal densities $\left(\mathrm{ng} \mathrm{cm}^{-2}\right)$ rather than as weight fractions.

The nature of the RBS spectrum makes it difficult to separate contributions from the oxygen in the filtered particles from those in the filter substrate. To obtain the best estimate of the $\mathrm{Fe}: \mathrm{O}$ ratio of the particles, we adopted the following procedure. The RBS spectrum was simulated with the RUMP program (Doolittle 1985), modified to include proton inelastic scattering crosssections and an automatic fitting routine (implemented in the Oxford data analysis software, Grime et al. 1991).

The sample was modeled in two layers: the particle (layer 1) consisting of FeOx of variable thickness, $t$, and the filter substrate (layer 2) consisting of $\mathrm{CO} y$ of infinite thickness. The following procedure then was followed. 1. Assuming the thickness of layer 1 is zero, obtain an initial composition for the substrate (vary $y$ to obtain the best fit of the simulation to the $\mathrm{C}$ and $\mathrm{O}$ edges in the data). 2 . Vary the thickness and composition of layer $1(t$ and $x)$ to obtain the best fit to the $\mathrm{Fe}$ and $\mathrm{O}$ peaks from the particles. 3. Vary the thickness and composition of layer 1 and the composition of layer 2 to get the best overall fit. This procedure gives the best estimate of particle composition and thickness. 4. To assess the error on the $\mathrm{O}$ determination, we varied $x$ around the best-fit value, adjusting $t$ to maintain the best fit, and subjectively took the error to be the range of $x$ which visibly made an inappreciable difference to the fit of the simulation to the measured RBS spectrum. The errors estimated by this procedure have no statistical basis, but merely serve as a guide to the range of stoichiometric ratios for $\mathrm{Fe}$ and oxygen that are consistent with the observed RBS spectra.

Examination of 50- $\times 50-\mu \mathrm{m}$ maps in which concentration is represented by the density of points (Fig. 2) showed that Fe was present predominantly in clusters measuring $\sim 5 \mu \mathrm{m}$ across. The secondary electron map, which gives an impression of topography in a similar fashion to a scanning electron microscope, revealed that the $\mathrm{Fe}$ clusters were coincident with the areas of the filter containing the most material. $S$ was uniformly distributed over the scanned area and $P$ showed only very slight signs of clustering, but there was a pattern in the $\mathrm{Mn}$ and to a lesser extent $\mathrm{Ca}$ maps that indicated a distribution similar to Fe. Standard linear correlation coefficients were calculated for pairs of elements for each pair of pixels in the mapped area. Because of the relatively low counts, the correlation coefficients were

Fig. 2. Representation of the concentration of $\mathrm{Ca}, \mathrm{Cu}, \mathrm{Fe}, \mathrm{Mn}, \mathrm{P}, \mathrm{S}$, and $\mathrm{Zn}$ in a $50-\mu \mathrm{m}^{2}$ area of filter. The denser the points, the higher the concentration. The secondary electron map (SEM) provides a representation of topography with high spots represented by the lighter image. Points $A, B$, and C were analyzed by a 1-mmdiameter beam, with the results presented in Table 1 . 

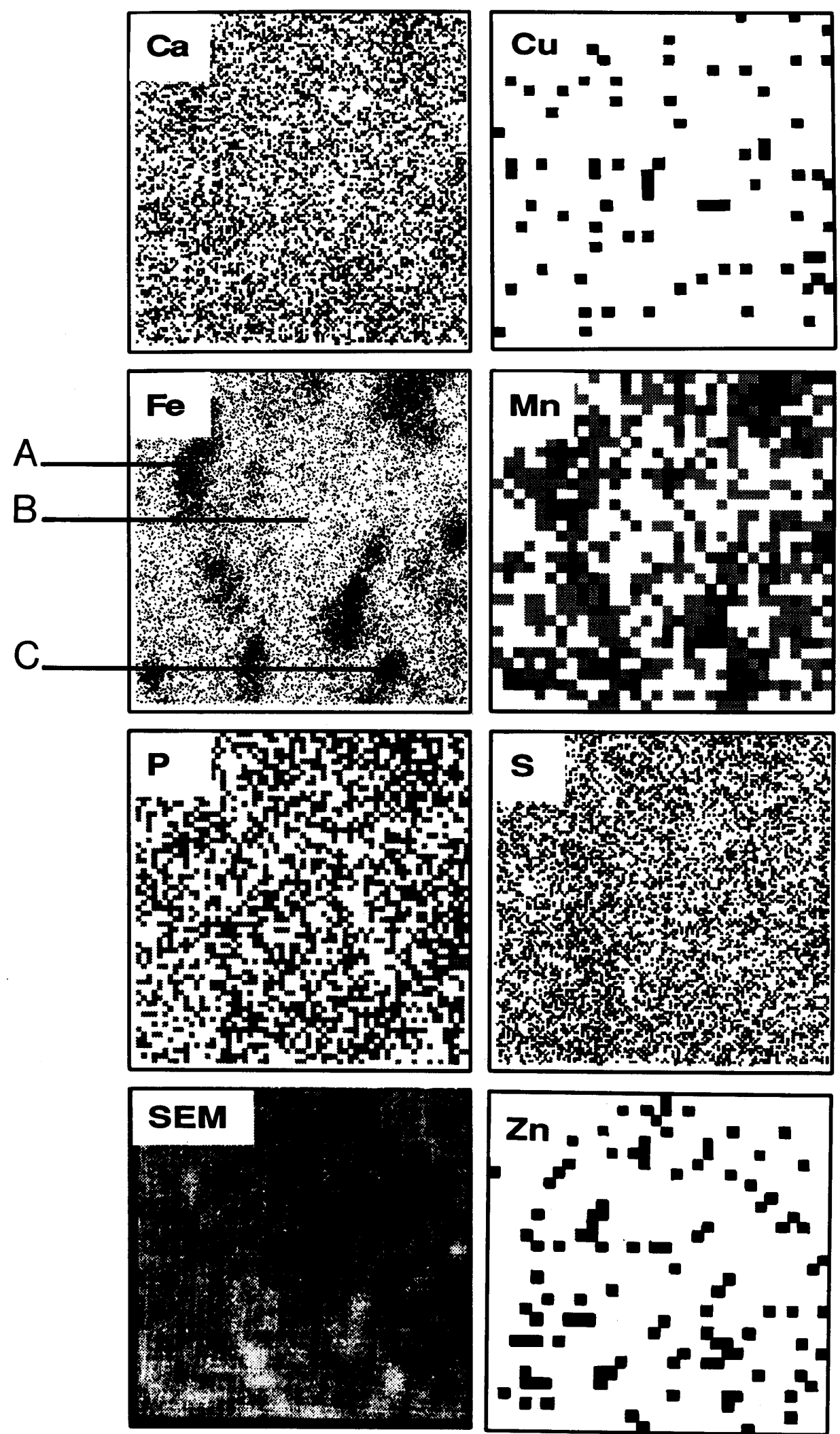
Table 1. Areal density (AD) of each element $\left(\mathrm{ng} \mathrm{cm}^{-2}\right)$ and concentration as a $w \mathrm{t} \%$ of $\mathrm{Fe}(\% \mathrm{Fe})$ and as a wt $\%$ of total elements (\%tot), including oxygen from RBS (A and C) or estimated stoichiometry (B) (\%tot) in 1- $\mu \mathrm{m}$ spots $A, B$, and $C$. The analyses are generally accurate to better than $10 \%$.

\begin{tabular}{|c|c|c|c|c|c|c|c|c|c|}
\hline & \multicolumn{3}{|c|}{$\bar{A}$} & \multicolumn{3}{|c|}{ B } & \multicolumn{3}{|c|}{$\mathrm{C}$} \\
\hline & $\mathrm{AD}$ & $\% \mathrm{Fe}$ & $\%$ tot & $A D$ & $\% \mathrm{Fe}$ & \%tot & $\mathrm{AD}$ & $\% \mathrm{Fe}$ & \%tot \\
\hline $\mathrm{Ca}$ & 860 & 1.9 & 1.2 & 490 & 18 & 6.4 & 1,100 & 2.1 & 1.4 \\
\hline $\mathrm{Cl}$ & 120 & 0.26 & 0.16 & 81 & 2.9 & 1.1 & 190 & 0.4 & 0.3 \\
\hline $\mathrm{Cr}$ & $<10$ & $<0.02$ & $<0.01$ & 2.9 & 0.10 & 0.04 & 35 & 0.07 & 0.05 \\
\hline $\mathrm{Cu}$ & 30 & 0.07 & 0.04 & 34 & 1.2 & 0.4 & $<14$ & $<0.03$ & $<0.02$ \\
\hline $\mathrm{Fe}$ & 46,000 & 100 & 64 & 2,800 & 100 & 36 & 52,000 & 100 & 68 \\
\hline $\mathrm{K}$ & 200 & 0.44 & 0.28 & 270 & 9.6 & 3.5 & 240 & 0.5 & 0.3 \\
\hline $\mathrm{Mn}$ & 360 & 0.78 & 0.50 & 120 & 4.3 & 1.6 & 460 & 0.9 & 0.6 \\
\hline $\mathbf{P}$ & 1,000 & 2.2 & 1.4 & 920 & 33 & 12 & 1,600 & 3.1 & 2.1 \\
\hline $\mathrm{Si}$ & $<400$ & $<0.9$ & $<0.6$ & $<560$ & $<0.20$ & $<7$ & $<160$ & $<0.3$ & $<0.2$ \\
\hline $\mathbf{S}$ & 920 & 2.00 & 1.3 & 960 & 35 & 13 & 1,600 & 3.1 & 2.1 \\
\hline $\mathrm{Ti}$ & $<30$ & $<0.07$ & $<0.04$ & $<30$ & $<1$ & $<0.4$ & $<30$ & $<0.06$ & $<0.04$ \\
\hline $\mathrm{Z}$ & 94 & 0.21 & 0.13 & 46 & 1.6 & $\begin{array}{r}0.4 \\
0.6\end{array}$ & 150 & 0.3 & 0.2 \\
\hline $\mathrm{O}$ & 21,600 & 47 & 30 & 2,000 & 71 & 26 & 18,000 & 35 & 24 \\
\hline$\Sigma$ & 71,500 & & & 7,650 & & & 75,700 & & \\
\hline
\end{tabular}

low, but the highest values were obtained between $\mathrm{Fe}$ and $\mathrm{Mn}$ and $\mathrm{Ca}$, supporting the visual interpretation.

Neither manganese oxides, which are readily reduced in the presence of $\mathrm{Fe}$ (II) and sulfides (Myers and Nealson 1988), nor manganese carbonate, which is undersaturated, with a ratio of IAP/K $\mathrm{K}_{\mathrm{sp}}$ of 0.22 (Stumm and Morgan 1981), are likely to account for the presence of Mn. It may be that the Mn is simply present as adsorbed $\mathrm{Mn}$ (II) ions. Such an explanation was suggested previously when a similar ratio of Fe to $\mathrm{Mn}$ was found in iron sulfide particles (Davison and Dickson 1984).

Three $1-\mu \mathrm{m}$ areas indicated in Fig. 2 as $\mathrm{A}, \mathrm{B}$, and $\mathrm{C}$ were selected for more detailed analysis (Table 1). Spots $A$ and $C$, which were in Fe clusters, were dominated by $\mathrm{Fe}$ with low, but appreciable concentrations of $\mathrm{S}(1.3$ and $2.1 \%), \mathrm{P}(1.4$ and $2.1 \%)$, and $\mathrm{Ca}$ (1.2 and 1.4\%). The RBS spectrum indicated a stoichiometry of $\mathrm{FeO}_{1.65 \pm 0.25}$ for $\mathrm{A}$ and $\mathrm{FeO}_{1.22 \pm 0.3}$ for $\mathrm{C}$. Due to the difficulties of background correction, there are large uncertainties in stoichiometry and, moreover, the $1-\mathrm{mm}$ beam may be averaging several very small $\mathrm{Fe}$ particles. A mineral phase cannot therefore be unequivocally assigned to these oxides. It is noteworthy, however, that the composition of $\mathrm{A}$ could be attributed to ferrihydrite $\left(\mathrm{Fe}_{2} \mathrm{O}_{3} \cdot n \mathrm{H}_{2} \mathrm{O}\right)$, while within $\mathrm{C}$ iron may be in the form of mag- netite $\left(\mathrm{Fe}_{3} \mathrm{O}_{4}\right)$ or possibly hematite (a$\mathrm{Fe}_{2} \mathrm{O}_{3}$ ), maghemite (g- $\left.\mathrm{Fe}_{2} \mathrm{O}_{3}\right)$, or a vacuuminduced dehydration product of ferrihydrite $\left(\mathrm{Fe}_{2} \mathrm{O}_{3} \cdot n \mathrm{H}_{2} \mathrm{O}\right)$. Thus, the stoichiometries deduced from the RBS spectra are consistent with phases of iron oxides known (Hilton 1990) to exist in such waters. The low concentrations of $\mathrm{Si}<0.6 \%$ indicate that these areas of the filter contain negligible amounts of clay minerals and that biogenic silica is not a major component.

The analysis of area B, representing an area of the filter with relatively low coverage of material and with uniform concentrations of all elements (Fig. 2), was markedly different from $\mathrm{A}$ and $\mathrm{C}$. It comprised $\mathrm{Fe}$ $(36 \%), \mathrm{S}(13 \%), \mathrm{P}(12 \%)$, Ca (6.4\%), and $\mathrm{K}$ $(3.5 \%)$, with appreciable concentrations of $\mathrm{Mn}(1.6 \%)$ and $\mathrm{Cl}$ (1.1\%) (Table 1). Although this area of the filter is apparently rich in iron sulfide, its composition is not simple, as it contains so much $\mathrm{P}$ and $\mathrm{Ca}$, elements not previously measured in black lacustrine suspensions. The distribution of $\mathrm{Mn}$ is clustered, like that of the Fe (Fig. 2), but it is proportionately more concentrated in the sulfide particles (Table 1). Mn at concentrations of $4-16 \%$ of the Fe, similar to that found here, has been reported previously in black particles from this lake (Davison and Dickson 1984).

The measured elemental ratio corresponds to a molar stoichiometry of $\mathrm{Fe}_{1.0}$ 
$\mathrm{S}\left({ }_{0.60}\right) \mathrm{P}\left({ }_{0.60}\right) \mathrm{Ca}_{0.24} \mathrm{~K}_{0.14}$. It is likely that there is an iron sulfide phase present in this material with a $1: 1$ stoichiometry because the IAP in these waters corresponds to that for amorphous ferrous sulfide and sulfide can be liberated from the particles with dilute acid (Davison and Heaney 1978), a test which is fairly diagnostic for iron monosulfides. Moreover on this sampling occasion the particles appeared black and the anoxic water smelled distinctly of $\mathrm{H}_{2} \mathrm{~S}$. It is unlikely, then, that the sulfur observed on this part of the filter can be attributed to $S$ incorporated in biological material. Inspection of the elemental map of S shows that it is distributed evenly over the measured filter including the areas occupied by the iron oxides. The implication is that the lake water contains a suspension of fine iron sulfide particles in which large particles or aggregates of iron oxides are interspersed. Particles in a natural water such as this will inevitably have a biogenic component. However, the low percentage for Si (Table 1) and the attribution of the uniformly distributed $\mathrm{S}$ component to FeS suggests that biogenic components are of minor importance in these particles.

To be able to calculate the percentage composition of the material, we need to know the full elemental composition, including oxygen. Unfortunately the material on the filter was too thin to estimate accurately the stoichiometry of $F e$ to oxygen from the RBS spectrum. The best fit was $F_{1.0}$ $\mathrm{O}_{2.34}$, but the fit was insensitive to $\mathrm{O}$, giving an unquantifiable uncertainty. Therefore, for the purposes of this calculation, it was assumed that the material was entirely inorganic. The following simple mixture of components (molar ratios in parentheses) $\mathrm{FeS}(0.6), \mathrm{FeO}_{1.5}(0.04), \mathrm{FePO}_{4}$ (0.36), $\mathrm{CaHPO}_{4}(0.10), \mathrm{CaKPO}_{4}(0.14)$-replicates the measured ratios of $\mathrm{Fe}, \mathrm{S}, \mathrm{P}, \mathrm{Ca}$, and $\mathrm{K}$. This assumed composition results in a ratio of iron to oxygen of $\mathrm{FeO}_{1.0}: \mathrm{O}_{2.46}$, enabling calculation of the percentage composition (Table 1).

$P$ and Ca observed on the filter may simply reflect a uniform biogenic component, but in view of the absence of any other evidence for the presence of biological material, an alternative origin for a substantial proportion of these elements appears likely. It is instructive to compare their ratios with those observed in other particles. Iron oxide particles formed higher in the water column of Esthwaite Water in a sulfide-free region contain $\mathrm{P}$ and $\mathrm{Ca}$ in the stoichiometry $\mathrm{Fe}_{1.0}$ $\mathrm{P}_{\text {0.055-0.14 }} \mathrm{Ca}_{\text {0.012-0.02 }}$ (Tipping et al. 1981). In a hard-water lake, similarly formed particles had a regular stoichiometry of $\mathrm{Fe}_{1.0} \mathrm{P}_{0.25}$ $\mathrm{Ca}_{0.19}$ and a biogenic origin for $\mathrm{P}$ and $\mathrm{Ca}$ was ruled out (Buffle et al. 1989).

The material of area $B$ appears to have higher proportions of $\mathrm{P}$ and $\mathrm{Ca}$, but the ratio of $\mathrm{Ca}: \mathrm{P}(0.4)$ is consistent with that observed by Tipping et al. (1981) (0.2-0.5) in iron oxide particles higher in the water column. It is possible that the $1-\mu \mathrm{m}$ beam is analyzing a mixture of different small particles; more likely, becausc a $1.2-\mu \mathrm{m}$ poresize filter was used for their collection, it reflects the composition of individual particles, even if they are colloidal aggregates. Moreover, the areal densities of S, P, Ca, and $\mathrm{K}$ for points $\mathrm{A}, \mathrm{B}$, and $\mathrm{C}$ are within a factor of 2 of one another (Table 1), indicating that there is a fairly uniform distribution of material similar to $B$, with additional local concentrations of iron oxide particles.

The observed elemental ratios suggest that black iron sulfide particles are formed from sinking iron oxide particles originating higher in the water column in a sulfide-free zone. Some of the iron oxide is remobilized into solution as it is reduced to $\mathrm{Fe}(\mathrm{II})$, possibly by reaction with $\mathrm{S}(-\mathrm{II})$, but $\mathrm{Ca}$ and $\mathrm{P}$ remain as an integral part of the particle. By this process $\mathrm{Ca}$ and $\mathrm{P}$ become concentrated with respect to Fe. When solution concentrations are such that the IAP for amorphous $\mathrm{FeS}$ is exceeded, it can also form at the surface of the particle as Fe is reduced. Thus FeS is incorporated in, or associated with, the particle. The $1: 1$ stoichiometric ratio of $\mathrm{Fe}$ (III) to $\mathrm{Fe}$ (II) which Buffle et al. (1989) found in iron oxide particles may represent the first stage of the reduction process as the particles sink through the water column.

The coexistence of iron oxide and iron sulfide particles indicates that either the supply of sulfide is limiting or that some iron oxide particles are unreactive. Al- 
though the above rationale is consistent with the data, it depends on the $\mathrm{Ca}$ and $\mathrm{P}$ observed in these particles not being attributable to finely dispersed biological material in the deep anoxic water. Formation of FeS by precipitation could be an equally plausible mechanism if $\mathrm{Ca}$ and $\mathrm{P}$ simply reflect the presence of a biogenic component.

There is a considerable amount of $\mathrm{Zn}$ (1,300-2,000 ppm) associated with the iron oxide particles (Table 1), but there is much more $\mathrm{Zn}(6,000 \mathrm{ppm})$ and $\mathrm{Cu}(4,000 \mathrm{ppm})$ present in the FeS-rich particles. Measurements of dissolved $\mathrm{Zn}$ and $\mathrm{Cu}$ concentrations in this lake have shown that they are uniformly low $\left(\mathrm{Zn}<5, \mathrm{Cu}<1 \mathrm{mg} \mathrm{liter}^{-1}\right)$ with no evidence for any substantial increase in the bottom waters (Morfett et al. 1988). The higher concentrations of $\mathrm{Zn}$ and $\mathrm{Cu}$ in the iron sulfide phase possibly reflect the insolubility of their sulfides (Emerson et al. 1983). The $\mathrm{Zn}: \mathrm{S}$ ratios in particles $\mathrm{A}, \mathrm{B}$, and $C(0.10,0.05$, and 0.10$)$ are sufficiently similar to support the suggestion that $\mathrm{Zn}$ is primarily present as its sulfide. Moreover, the distribution of $\mathrm{Zn}$ and $\mathrm{Cu}$ on the $50-\mu \mathrm{m}$ grid was uniform, consistent with the distribution of S (Fig. 2).

Although caution must be exercised when interpreting so few measurements, some clear features emerge. Iron sulfide particles are distributed uniformly across the filter and are associated with appreciable concentrations of $\mathrm{P}, \mathrm{Ca}$, and $\mathrm{K}$. Iron oxide particles or clusters $(\sim 5 \mu \mathrm{m})$ coexist with the iron sulfide particles. To our knowledge this is the first use of Rutherford backscattering to estimate the contribution of oxygen in environmental particles. This application shows great promise, especially if the particles can be collected on an oxygen-free substrate, which would increase the precision and greatly simplify the fitting procedure.

W. Davison

Institute of Environmental and

Biological Sci.

Environmental Sci. Div.

Lancaster University

Lancaster LA1 4YQ, U.K.
G. W. Grime

Department of Nuclear Physics

University of Oxford

Keble Road

Oxford OX1 3RH, U.K.

\section{Woof}

Institute of Freshwater Ecology

The Ferry House

Ambleside, Cumbria LA22 OLP, U.K.

\section{References}

Balistrieri, L. S., J. W. Murray, AND B. Paul. 1992. The biogeochemical cycling of trace metals in the water column of Lake Sammamish, Washington: Response to seasonally anoxic conditions. Limnol. Oceanogr. 37: 529-548.

Buffle, J., R. R. Devitre, D. Perret, AND G. G. LePPARD. 1989. Physico-chemical characteristics of a colloidal iron phosphate species formed at the oxic-anoxic interface of a eutrophic lake. Geochim. Cosmochim. Acta 53: 399-408.

- O. Zali, J. Zumstein, AND R. R. Devitre. 1987. Analytical methods for the direct determination of inorganic and organic species: Seasonal changes of iron, sulfur, and pedogenic and aquogenic organic constituents in the eutrophic Lake Bret, Switzerland. Sci. Total Environ. 46: 4159.

Chu, W. K., J. W. Mayer, AND M. A. Nicolet. 1978. Backscattering spectrometry. Academic.

CoOK, R. B. 1984. Distribution of ferrous iron and sulfide in an anoxic hypolimnion. Can. J. Fish. Aquat. Sci. 41: 286-293.

Davison, W. 1991. The solubility of iron sulfides in synthetic and natural waters at ambient temperature. Aquat. Sci. 53: 309-329.

, AND D. P. E. Dickson. 1984. Mossbauer spectroscopic and chemical studies of particulate iron material from a seasonally anoxic lake. Chem. Geol. 42: 177-187.

, AND S. I. HEANEY. 1978. Ferrous iron-sulfide interactions in anoxic hypolimnetic waters. Limnol. Oceanogr. 23: 1194-1200.

DoolitteE, L. R. 1985. Algorithms for the rapid simulation of Rutherford backscattering spectra. Nucl. Instr. Meth. 9: 344-351.

Emerson, S. R., L. A. JACOBS, AND B. Tebo. 1983. The behaviour of trace metals in marine anoxic waters: Solubilities at the oxygen-hydrogen sulfide interface, p. 579-608. In Trace metals in sea water. NATO Conf. Ser. 4, V. 13. Plenum.

Grime, G. W., M. Dawson, M. Marsh, I. C. McARTHUR, AND F. WATt. 1991. The Oxford submicron nuclear microscopy facility. Nucl. Instr. Meth. 54: 52-63.

$\longrightarrow$, AND F. WATT. 1990. Nuclear microscopyElemental mapping using high energy ion beam techniques. Nucl. Instr. Meth. 50: 197-207. 
Hilton, J. 1990. Greigite and the magnetic properties of sediments. Limnol. Oceanogr. 35: 509-520.

JAKSIC, M., G. W. GRIME, J. HENDERSON, AND F. WATt. 1991. Quantitative PIXE analysis using a scanning proton microbeam. Nucl. Instr. Meth. 54: $491-498$.

Johansson, S. A. E., AND J. L. Campbell. 1988. PIXE-A novel technique for elemental analysis. Wiley.

MORFETT, K. D. 1988. Trace metal dynamics in a seasonally anoxic lake. Ph.D. thesis, Lancaster Univ. 175 p.

- W. W. DAVISON, AND J. HAMILTON-TAYLOR. 1988. Trace metal dynamics in a seasonally anoxic lake. Environ. Geol. Water Sci. 11: 107-114.
Myers, C. R., AND K. NeAlson. 1988. Microbial reduction of manganese oxides: Interactions with iron and sulfur. Geochim. Cosmochim. Acta 52: 2727-2732.

Stumm, W., AND J. J. Morgan. 1981. Aquatic chemistry, 2nd ed. Wiley-Interscience.

Tipping, E., C. Woof, AND D. CoOKe. 1981. Iron oxide from a seasonally anoxic lake. Geochim. Cosmochim. Acta 45: 1411-1419.

Submitted: 6 December 1991 Accepted: 25 June 1992 Revised: 23 July 1992

\section{Toxic compounds isolated from Microcystis PCC7806 that are more active against Daphnia than two microcystins}

\begin{abstract}
Microcystis strain PCC7806 was toxic to Daphnia pulicaria. The toxicity of a crude water extract from lyophilized cells of Microcystis was determined in order to characterize the toxic compound. The $\mathrm{LC}_{50}$ of the crude extract was 47.4 $\mu \mathrm{l} \mathrm{ml} \mathrm{m}^{-1}$. The crude extract was fractionated by solid-phase extraction and tested for toxicity. The microcystins in the different fractions were analyzed by HPLC. The crude extract contained 22 $\mu \mathrm{g} \mathrm{ml}^{-1}$ microcystin-LR and $12.3 \mu \mathrm{g} \mathrm{ml}^{-1}$ 3-desmethylmicrocystin-LR, the C-18 eluate contained 16.3 and $9.1 \mu \mathrm{g} \mathrm{ml}^{-1}$ of these compounds, respectively. Neither compound was detected in the C-18 cartridge-passed crude extract. Nevertheless the C-18 cartridge-passed fraction was toxic to Daphnia. Hence I conclude that the two microcystins in the crude water extract are not the compounds in Microcystis PCC7806 which are toxic to Daphnia.
\end{abstract}

Microcystis spp. are the most common bloom-forming cyanobacteria in lake ecosystems. The toxicity of Microcystis blooms to warm-blooded animals has been reported worldwide (Carmichael 1988). In recent years, however, many Microcystis strains

\section{Acknowledgments}

I thank W. Lampert for critical comments on the manuscript, and W. R. DeMott, W. W. Carmichael, and an anonymous reviewer for comments and critiques. N. Zehrbach and I. Grüneberg provided linguistic improvements. have been reported to be toxic to Daphnia (Lampert 1981a; Peñaloza et al. 1991; Jungmann et al. 1991). Daphnia avoids ingesting such Microcystis strains which can be detected by measuring the filtering rate of Daphnia. Daphnids whose only food source is Microcystis cells die more rapidly than starved animals (Lampert 1981a), indicating that Microcystis cells contain a compound (compounds) toxic to Daphnia. In contrast DeBernardi et al. (1980) reported that they sampled Microcystis sp. which exhibited no toxicity to Daphnia but provided a suitable food source for the animals. Comparison of these results show that not every Microcystis strain is toxic to daphnids. The toxicity of a Microcystis strain and its ability to reduce the grazing pressure of the zooplankton have been suggested to be an algal defense that favors formation of a bloom (Lampert $1981 a, b$ ). It is therefore important to characterize the toxic compound in more detail.

The microcystins (cyanoginosine) compounds in Microcystis, which are cyclic hepatotoxic heptapeptides with a known amino-acid sequence (Botes et al. 1985), are toxic to many vertebrates. They have been isolated from various Microcystis strains (Carmichael 1988; Codd et al. 1989). They 